\title{
INFECCIONES INTRA-ABDOMINALES
}

Jorge Cabarca Montemiranda MD*

\section{Resumen}

Es importante comprender los mecanismos de defensa de la cavidad abdominal así como sus diferentes células residentes y funciones diversas ante una agresión, para generar una respuesta inflamatoria peritoneal temprana y tardía a la infección. Conocer la diferente flora gastrointestinal permite entender la etiología y agentes causales de los procesos inflamatorios e infecciosos intrabdominales. La clasificación y diagnóstico adecuados permiten establecer un tratamiento apropiado, tanto en el manejo antibiótico como el quirúrgico; los diferentes tipos de laparotomía para limpieza de la cavidad peritoneal permiten un mejor control de la infección y evitar posibles complicaciones que progresan hacia una respuesta inflamatoria sistémica y una disfunción multiorgánica. El presente artículo trata de abarcar dichos temas con el fin de tener adecuados conocimientos para el manejo de las infecciones intrabdominales. Materiales y métodos: se realizó una búsqueda en la literatura utilizando las palabras claves en Medline, Cochrane y Pubmed, además de textos guías. Resultados: de los numerosos artículos se seleccionaron los que se mencionan al final en las lecturas recomendadas.

Palabras clave: absceso intraabdominal, sepsis, peritonitis, antibióticos, flora intestinal.

Albreviaturas: IIA, infección intrabdominal; TBX, tromboxano; PGD, prostaglandinas; IL, interleuquina; IGF, factores de crecimiento de insulina; FNT, factor de necrosis tumoral; PT, peritoneo; CABD, cavidad abdominal.

\section{Abstract}

It is important to understand the defense mechanisms of the abdominal cavity as well as the various resident cells and their diverse functions upon aggression to generate early and late peritoneal inflammatory responses to infection. Knowledge on the bacteria which constitute the intestinal flora allows identifying the etiology and causative agents of the inflammatory processes and intra-abdominal infections. An adequate classification and diagnosis enables an appropriate therapeutic approach both as antimicrobial therapy as well as surgery. Different types of laparotomy incisions for peritoneal cleaning provide better infection control and prevent possible complications and progression to systemic inflammatory response and multiple organ failure. This review tries to cover these topics in order to provide with sufficient knowledge to treat intra-abdominal infections. Materials and Methods: a search of literature in Medline, Cochrane and Pubmed was conducted using key words and guide texts. Results: the articles selected, among many, are mentioned at the end of this paper in the recommended reading list.

Key Words: intra-abdominal abscess, sepsis, peritonitis, antibiotics, intestinal flora.

Fecha recibido: noviembre 14 de 2007-Fecha aceptado: enero 9 de 2008

* Residente de ginecología y obstetricia. Fundación Universitaria de Ciencias de la Salud. Bogotá D.C. Colombia. 


\section{Mecanismos de defensa de la CABD}

El PT pertenece a una familia de tejidos conocidos como serosas. Se acepta que tiene la misma área que la piel, con un promedio de $177 \mathrm{~cm}^{2} / \mathrm{k}$. Está diseñada para combatir la invasión bacteriana mediante tres mecanismos: 1)separación de bacterias por medio de los estomas diafragmáticos, 2) exudación celular y fagocitosis y 3) secuestro de bacterias y formación de abscesos. La exposición del PT a una bacteria promueve la respuesta de defensa tanto innata como adquirida en un sistema secuencial y coordinado de interacciones de células mesenquimales del sistema inmune y no inmune.

\section{Células de la CABD}

1. Macrófagos: el PT contiene macrófagos en diferentes estados de activación. Cuando no hay infección existe una pequeña población $\left(10^{3}-10^{4}\right)$, que varía de un individuo a otro. Ante un estímulo crónico migran al peritoneo macrófagos cada vez más inmaduros, posiblemente por la pérdida continua por drenaje, acompañada por el incremento en la habilidad de sintetizar citoquinas inflamatorias. Ante un estímulo inflamatorio agudo, la infiltración y acumulación de estas células en la cavidad peritoneal tiene un máximo a las 24 horas del comienzo del influjo de neutrófilos. Secretan al menos 80 diferentes tipos de productos incluyendo factores de coagulación, componentes de la cascada del complemento, enzimas, citoquinas, factores de crecimiento, eicosanoides y prostanoides, especies de reactantes de oxígeno y proteínas de matriz extracelular entre otras. Liberan productos de ciclooxigenasa y lipooxigenasa del metabolismo del ácido araquidónico: $\mathrm{TXB}_{2} \mathrm{y} \mathrm{PGE}_{2}$. Durante una peritonitis los macrófagos residentes producen citoquinas proinflamatorias (IL-1 $1_{\mathrm{B}}, \mathrm{TNF}$ alfa).

2. Mesotelio: la barrera mesotelial es la interfase entre la sangre y la cavidad serosa; las microvellosidades y vesículas picnóticas cambian su número ante una variedad de estímulos y agentes químicos y la abundancia de microvellosidades en la superficie apical incrementa en forma notable la función de superficie del PT. Estas células se pueden diferenciar de las endoteliales y macrófagos de los tejidos por la morfología y los receptores de membrana (Tabla 1).

Las células mesoteliales expresan ICAM-1 y V-CAM en la superficie que incrementan la exposición a TNF alfa e IFN gama. Las endoteliales no expresan

\begin{tabular}{|c|c|c|c|}
\hline & Células mesoteliales & Endotelio & $\begin{array}{c}\text { Macrófagos } \\
\text { peritoneales }\end{array}$ \\
\hline $\begin{array}{l}\text { MICROFILAMENTOS } \\
\text { Citoqueratina } 8 \\
\text { Citoqueratina } 18 \\
\text { Vimentin }\end{array}$ & $\begin{array}{l}+ \\
+ \\
+\end{array}$ & $\begin{array}{l}- \\
+\end{array}$ & $\begin{array}{l}- \\
-\end{array}$ \\
\hline $\begin{array}{l}\text { ANTÍGENOS PRO-COAGULANTES } \\
\text { Factor VIII }\end{array}$ & - & + & - \\
\hline $\begin{array}{l}\text { RECEPTORES DE ADHESIÓN } \\
\text { ICAM-I/CD54 } \\
\text { ICAM-2/CD I02 } \\
\text { V-CAM/CDI06 } \\
\text { E-selectina } \\
\mathrm{B}_{1} \text { integrinas } \\
\mathrm{B}_{2} \text { integrinas } \\
\mathrm{B}_{3} \text { integrinas }\end{array}$ & $\begin{array}{l}+ \\
- \\
+ \\
- \\
+ \\
- \\
+\end{array}$ & $\begin{array}{l}+ \\
+ \\
+ \\
+\end{array}$ & $\begin{array}{l}+ \\
+ \\
- \\
- \\
+ \\
+\end{array}$ \\
\hline $\begin{array}{l}\text { MARCADORES DE LEUCOCITOS } \\
\text { CDI } 6 \\
\text { HLA-DA }\end{array}$ & - & & $\begin{array}{l}+ \\
+\end{array}$ \\
\hline
\end{tabular}


ICAM-2 o E-selectina. Las mesoteliales del PT sintetizan citoquinas pro-inflamatorias (G-CSF, GM-CSF, M-CSF, IL-1 alfa, IL-1 beta, IL-6, IL-8) y factores de crecimiento (TGFbeta, IGF-II), que aumentan durante un estimulo inflamatorio o infeccioso. En presencia de citoquinas derivadas de macrófagos (IL-1beta, TNFalfa) el mesotelio produce IL-1alfa e IL-2 bioactivos, así como otras quimiocinas, proteína quimiotáctica de monocitos (MPC-1), proteína inflamatoria de macrófagos y RANTES (regulación sobre la activación de la expresión y secreción de células $\mathrm{T}$ ), pero no citoquinas derivadas de células T. Además, expresan receptores para IGF-I e IGF-II así como de insulina y transcriptores de RNA para IGF-II, sugiriendo que pueden funcionar como factor de crecimiento autocrino y paracrino para modular el crecimiento de estas células.

3. Linfocitos: se encuentran en los sitios lechosos del epipión, el fluido peritoneal y el drenaje de nódulos linfáticos. Esto sugiere que el PT puede proveer un microambiente que favorece la expansión y acumulación de un grupo particular de células $\mathrm{T}$ o podría servir como un sitio para diferenciación de ellos independiente del timo. En efecto, el líquido peritoneal contiene una población heterogénea de células con capacidad para detectar virus y bacterias. Los distintos subtipos de células B de fenotipos CD5 son raras en la sangre o nódulos linfáticos pero comunes en el PT en especial en el epiplón fetal. Por encima del $65 \%$ de las células B peritoneales expresan antígenos de superficie CD5, lo cual permite repoblar la lámina propia intestinal con células productoras de IgA y contribuye con la mayoría de IgM sérica. Entre sus funciones está la respuesta a lipopolisacáridos T independientes (M. meningitidis capsulado, H. influenza y S. pneumoniae). Entre 7 y $8 \%$ de la población de linfocitos peritoneales son células natural klillers (CD3, CD7, CD16, CD56) aunque la mayoría son CD2 (42\%).

En áreas donde se acumulan macrófagos en gran número, el epiplón aparece engrosado al contener puntos lechosos que migran a la CABD. Varios hechos caracterizan esa alta capilaridad de las estructuras omentales, como su posición bajo el mesotelio y su forma glomerular. El drenaje linfático peritoneal sigue un circuito separado que no está conectado con el sistema del conducto toráxico. Durante un proceso inflamatorio peritoneal los sitios lechosos constituyen la mayor ruta por la cual los leucocitos migran dentro de la CABD. El conducto toráxico es parte del circuito normal de recirculación de ciertas poblaciones de linfocitos y contiene enorme cantidad de estas células, las cuales pueden ser distribuidas en el sistema linfático intestinal.

\section{Respuesta inflamatoria temprana peritoneal a la infección}

La interacción entre el mesotelio y los macrófagos juega un papel central en la respuesta inicial a la infección peritoneal (fase de iniciación) así como durante la fase de amplificación para el control del reclutamiento de leucocitos y en los estadios tempranos de resolución (fase de curación).

El papel primario del mesotelio es amplificar e iniciar la respuesta peritoneal a la invasión de microorganismos mediante activación de la secreción de IL-8. Por otro lado, los macrófagos sintetizan y liberan $1 \mathrm{~L}-1 \beta$, y FNT- $a$ en presencia de bacterias o sus productos, lo cual libera citoquinas e icosanoides en la cavidad a través del mesotelio. El estrecho contacto entre el peritoneo parietal, visceral y epiplón, resultado de la respiración y peristalsis intestinal, facilita la intercomunicación entre las células.

Después de la inoculación intraabdominal, el fluido es filtrado hacia el peritoneo y la tasa de absorción depende del tamaño del inóculo. Partículas y células (por encima de $1 \mu \mathrm{m}$ de diámetro) se remueven a través de estomas y se llevan por los canales linfáticos del diafragma al conducto toráxico y a la circulación sanguínea en doce minutos con cada excursión diafragmática. La presencia de una unión de fibrina resulta en la saturación de las estomas disminuyendo la absorción trans-diafragmática. Además, otros factores influyen en la habilidad de la CABD para absorber grandes cantidades de bacterias y detritus, 
tales como la relación entre la presión intratoráxica e intraabdominal, la presencia de ascitis, íleo y la postura del paciente.

La estimulación con citoquinas derivadas de macrófagos, LPS de bacterias, IFN- $\delta$ derivado de células-T o la combinación de estos, estimula la síntesis de RNAm y la expresión de quimiocinas por el mesotelio. La IL8 es un potente quimioatrayente de neutrófilos y una de las primeras quimiocinas ( 24 horas) asociada con la superficie de la membrana basal de las células mesoteliales del PT. La MCP-1 y MIP-1 $\alpha$ se liberan después en la membrana apical de las células mesoteliales y son las mayores quimioatrayentes de monocitos (más de 24 horas) en la cavidad peritoneal.

El paso de proteínas durante la peritonitis bacteriana está relacionada con el contenido de prostaglandinas en el líquido peritoneal. Las citoquinas derivadas de macrófagos incrementan la expresión de ambas formas de ciclooxigenasa (Cox-1, Cox-2) en células mesoteliales dirigiendo la producción de 6-cetoPGF1 y PGE2. De otra parte, los macrófagos estimulados por bacterias incrementan la generación de leucotrienos dependiente de lipooxigenasa (LTB4, un gran quimioatrayente de neutrófilos). Durante una peritonitis se producen prostaglandinas vasodilatadores locales que contribuyen a la hiperemia y exudación de proteínas (albúmina y fibrina) por incremento de la permeabilidad post-capilar.

El proceso inflamatorio aumenta, en la superficie del endotelio y mesotelio, moléculas que sostienen la adhesión y migración de leucocitos. Las células mesoteliales expresan altos niveles de receptores de adhesión de la superfamilia de inmunoglobulinas ICAM/CD54 y VCAM/CD106, las cuales son ligandos de integrinas de los leucocitos CD11a/CD18 (linfocitos) y CD11b/CD18 (neutrófilos y macrófagos). Además, las células mesoteliales también expresan PECAM-1/CD31, que es esencial para que los neutrófilos crucen el endotelio a través de la matriz extracelular y del espacio submesotelial a la cavidad peritoneal a través de las uniones mesoteliales intercelulares.
Durante la amplificación de la respuesta inflamatoria temprana del PT a la invasión bacteriana, el exudado rico en fibrina pasa a la cavidad abdominal produciendo un tercer espacio, cuya presencia es esencial para el secuestro inicial de bacterias mediante el depósito de fibrina entre el peritoneo visceral y parietal, con la formación de adherencias organizadas y abscesos. La presencia de fibrina se debe en parte a la inactivación de la fibrinólisis durante la peritonitis. Varias células peritoneales pueden expresar factor tisular y actividad procoagulante debido al daño celular y el estímulo bacteriano. La interacción de neutrófilos con células mesoteliales activas libera proteasas oxígeno oxidativas, las cuales son las responsables de las alteraciones agudas observadas en la función de la membrana peritoneal.

\section{Respuesta tardía a la infección peritoneal}

El flujo de neutrófilos a la cavidad peritoneal causa un incremento en el número de monocitos que se diferencia muy rápido en macrófagos y son las células predominantes en el peritoneo en la resolución de la injuria quirúrgica y en el proceso de curación. En este estado los factores de crecimiento derivados de macrófagos, como el de crecimiento derivado de plaquetas (PDGF), de fibroblastos (FGF), de crecimiento epidérmico (EGF) y el parecido a insulina (IGF-I), estimulan la proliferación y expresión de diferentes funciones sobre una variedad de células en especial fibroblastos y mesotelio. El EGF y el FGF están involucrados en la transición de células mesoteliales de la fase Go a la S, mientras que el IGF-I estimula la proliferación al afectar la transición de la $\mathrm{S}$ a la $\mathrm{M}$. Esto sirve como señal para direccionar la reepitelización peritoneal y los procesos de reparación de los tejidos desde la matriz extracelular.

El factor $\beta$ de crecimiento transformador derivado del mesotelio es una poderosa señal quimiotáctica de fibroblastos que induce un profundo efecto sobre el dermatan sulfato. Además las células mesoteliales son el blanco del TGF- $\beta$, que potencia el reconocimiento de la actividad fibrinolítica y la acumulación de PAI-1. La fibrinólisis peritoneal es esencial para la 
prevención de adherencias y la resolución de exudados fibrosos. Varios factores potencian la formación de adherencias durante la infección intraabdominal, tales como el sangrado, ciertos procedimientos quirúrgicos sobre órganos sólidos (páncreas e higado), cirugías extensas e injurias como la peritonitis. Si la agresión persiste, la actividad fibrinolítica se suprime y los depósitos de fibrina se organizan mediante neo-angiogénesis y depósito de colágeno.

La formación de abscesos es la última fase patológica en la evolución de las infecciones intraabdominales. Contienen una flora polimicrobiana consistente en anaerobios obligados y especies facultativas, y pueden reproducirse en forma experimental con polisacáridos de Bacteroides fragilis. Se han detectado dos componentes polisacáridos en su cápsula, el $\mathrm{A}$ (PSA) y el B (PSB) esenciales en la prevención y formación de abscesos. Ambos polisacáridos inducen la producción de IL- $\beta$ y FNT- $\alpha$ por células mesoteliales, IL-8 por polimorfonucleares e IL-10 por macrófagos y linfocitos peritoneales. Esta última es una potente citoquina immunorreguladora tipo Th2 la que interviene en la respuesta inmune y parece ser efectiva en la secreción primaria de inmunoglobulinas.

\section{Ecología microbiológica de la flora gastrointestinal}

El tracto gastrointestinal normal contiene más de 400 especies de bacterias en íntima proximidad con la compleja red del tejido inmunológico y sirve como importante órgano de homeostasis inmune. Las alteraciones en la flora nativa han sido implicadas en la patogénesis de diversos grupos de desórdenes de dicha homeostasis como la cirrosis, tiroiditis autoinmune y artritis. La flora del tracto gastrointestinal normal se incrementa en número y diversidad del extremo proximal al distal. Los patrones de colonización difieren en los diferentes sitios anatómicos En la cavidad oral predominan los organismos gram positivos y anaerobios, el estómago y la parte proximal del intestino son relativamente estériles y numerosos organismos gram negativos aumentan en la parte distal del intestino. Los anaerobios aparecen en el colon.
La flora gastrointestinal comprende la relación de tres poblaciones microbianas. La autóctona comprende a aquellas que aparecen durante la evolución del animal, la macrobiótica consiste en los microorganismos del ambiente natural en el cual establecen residencia todos los miembros de la especie; estos dos grupos constituyen la flora nativa y se diferencian de los patógenos que se adquieren del ambiente y son capaces de establecer residencia en el tracto digestivo y producir enfermedades con alteración sistémica.

La flora nativa del tracto gastrointestinal se distribuye en dos compartimientos, el epitelio y el lumen. Algunos organismos atacan la mucosa intestinal, mientras otros viven en suspensión en el moco sobre el epitelio. Las variaciones en la composición de esta flora reflejan la complejidad de las interacciones entre organismo y huésped, lo cual mantiene la estabilidad biológica de la flora nativa. La simbiosis entre la colonización de microorganismos y el microambiente local asegura la estabilidad de la flora y sirve para inhibir la colonización de la mucosa por gérmenes potencialmente patógenos, fenómeno conocido como "resistencia a la colonización".

Los organismos libres en el lumen intestinal son más accesibles para muestras pero son menos representativos del componente estable de la flora nativa. Los estudios bacteriológicos de la flora gastrointestinal emplean una de estas tres técnicas de cultivo: la superficie de la mucosa de porciones accesibles (orofaringe y recto), la de fluidos o material expelido por el aparato digestivo o la muestra del contenido intestinal obtenido por dispositivos. Todos presentan inconvenientes para reflejar la verdadera flora GI.

a) Flora orofaríngea: consiste en esencia de Streptococcus, Actinomyces y anaerobios. Los gram negativos solo se encuentran en $6 \%$ de individuos sanos, pero sube a $75 \%$ en enfermos críticos hospitalizados; tal colonización es un factor de riesgo para desarrollar infección nosocomial del tracto respiratorio.

b) Flora gástrica: el estómago por lo regular es estéril o poblado con organismos como Streptococcus, 
Lactobacillus y cocos anaerobios; su número rara vez excede $10^{3} \mathrm{UFC} / \mathrm{ml}$. La Candida se halla en cerca del $30 \%$ de individuos normales y en una porción similar en pacientes con úlcera gástrica. El Helicobacter pylorii se considera como un componente de la flora de la mucosa del estómago en algunos individuos normales y juega un papel importante en la patogénesis de las gastritis, ulcera péptica y posiblemente en enfermedad maligna del estómago. La acidez es el factor responsable de mantener el estado de relativa esterilidad.

c) Flora del intestino delgado: se incrementa en forma cualitativa y cuantitativa de extremo proximal a distal; la bacteriología del duodeno es similar a la del estómago, mientras que la flora del íleon terminal es en esencia la misma del ciego. Los cocos gram negativos y los anaerobios se incrementan a lo largo del íleon con concentraciones de $10^{5}$ a $10^{8} \mathrm{UFC} / \mathrm{mL}$ en la porción terminal. No se encuentran virus.

c) Flora colónica: es una compleja mezcla de alrededor de 400 diferentes especies microbianas, con una relación anaerobios/aerobios de 1000 a 1. La concentración de bacterias en las heces puede exceder $10^{10} \mathrm{UFC} / \mathrm{mL}$, los especímenes obtenidos por aspiración del contenido del colon al momento de una laparotomía son dos a tres unidades logarítmicas más bajas. La Candida es un poco más común en las heces que en el intestino delgado y puede aislarse en $65 \%$ de las muestras. Los cultivos de la mucosa del colon y del intestino delgado reflejan la realidad del contenido luminal. La flora colónica incluye organismos espirales predominantes, favorecidos por su motilidad, la tensión de oxígeno local y la acidez de la mucina.

\section{Establecimiento y persistencia de la flora nativa}

El tracto gastrointestinal del feto es estéril. El Streptococus y la $E$. coli aparecen durante los primeros días de nacimiento, su número es alto en niños sin alimentación materna. Los anaerobios tales como el Bifidobacterium, Clostridium y Bacteroides serán evidentes en la primera semana. El Streptococus,
Bifidobacteria y E.coli son dominantes a las dos semanas. Las concentraciones de cocos anaerobios gram positivos, Bacteroides y Clostridium se incrementan por encima de los dos años y la composición fecal es similar a la del adulto.

\section{Regulación de la microbiología normal}

La estabilidad de la flora gastrointestinal se mantiene mediante mecanismos fisiológicos, microbiológicos e inmunológicos; su alteración puede inducir patrones anormales de colonización. La acidez gástrica es la principal responsable de la relativa esterilidad del estómago y el tracto gastrointestinal superior. Los organismos gram negativos son más susceptibles a su efecto bactericida. Al reducir el número de organismos en el duodeno y yeyuno, la acidez gástrica también regular la flora microbiana del intestino delgado.

El metabolismo de los ácidos biliares está regulado por los microorganismos intestinales, convirtiéndolos de primarios en secundarios y desconjugándolos en la luz intestinal. Los ácidos cólico y desoxicólico inhiben el crecimiento de enterococos, bacteroides y lactobacillos in vitro, mientras los ácidos biliares conjugados carecen de actividad inhibitoria. El papel de la bilis en la ecología microbiológica intestinal aun es incierto, aunque se ha sugerido que la influencia más importante es la prevención de la colonización por organismos que por lo regular no se encuentran en el tracto gastrointestinal.

En cuanto a la motilidad intestinal, el tránsito rápido por el estómago y el intestino delgado influye no solo en el número de organismos sino en su composición. La estasis está relacionada con el incremento en la concentración de anaerobios. La obstrucción intestinal resulta en un incremento significativo en la densidad de la flora del estómago y del intestino delgado. La flora microbiana del intestino influencia la motilidad. Diversos estudios han mostrado que el vaciamiento gástrico y la motilidad son mayores en animales con flora intacta que en animales libres de bacterias; el mecanismo de este efecto es desconocido. 


\section{Factores microbiológicos}

Los mecanismos por los cuales la flora autóctona regula los patrones de colonización gastrointestinal son complejos y no están bien definidos. El concepto de resistencia a la colonización describe la influencia inhibitoria ejercida por la flora nativa sobre la presencia de organismos extraños. Se ha definido desde el punto de vista cuantitativa como el número de organismos requeridos para establecer colonización fecal a un nivel mayor de $10^{3}$ UFC/ $\mathrm{mL}$, en el $50 \%$ de los animales expuestos y en forma cualitativa como el mecanismo biológico responsable para la prevención de colonización anormal por microorganismos patógenos. Se ha demostrado que el papel de la flora nativa para estabilizar la ecología microbiana del intestino se interrumpe ante la administración de antibióticos, como sucede en la colitis por C.dificile.

La producción de factores antimicrobianos por la flora nativa pueden inhibir o promover el crecimiento de otros organismos. Algunos ácidos grasos volátiles originados por bacterias anaerobias, en especial el acido butírico, inhiben el crecimiento de anaerobios facultativos y parece jugar un papel importante en la regulación del numero de $E$. coli, así como en la prevención del establecimiento de patógenos exógenos como la Shigella. La disminución de la concentración de los ácidos volátiles está asociada con la menor resistencia a la colonización de organismos anaerobios facultativos exógenos y endógenos. Una amplia variedad de bacterias gram negativas y positivas producen una serie de sustancias conocidas como bacteriocinas, las cuales inhiben el crecimiento de otras cepas. La colicina elaborada por E. coli es la más conocida para inhibir el crecimiento de otros organismos gram negativos. Los lactobacílos ejercen una influencia inhibitoria sobre el crecimiento de un número de especies bacterianas incluyendo S. aureus, E. coli, Salmonella y Clostridium. Los lactobacílos producen antibióticos naturales como acidophilin y bulgarican, así como peróxido de hidrógeno, los cuales inhiben el crecimiento de $S$. aureus y Pseudomonas, sin embargo también esti- mula la producción de anticuerpos IgA específicos para patógenos potenciales como S.typhi.

\section{Regulación inmunológica de la flora nativa}

La flora nativa ejerce una significativa influencia sobre la homeostasis del sistema inmune. La inmunoglobulina $A(\lg A)$ es un producto de las células epiteliales liberada hacia la luz intestinal. Aunque las células B del tejido linfoide del intestino es el sitio de su síntesis, la secreción es mayor en la circulación venosa portal que en la sistémica, sugiriendo que los tejidos que drenan a la sangre portal son los mayores sitios de producción. La función primaria biológica de la IgA es la prevención de la adhesión bacteriana a las células epiteliales. En el esputo inhibe la unión de pseudomona a las células epiteliales de la tráquea, así como la IgA urinaria ejerce un efecto inhibitorio similar con la unión de E. Coli a las células de la vejiga. La inmunidad mediada por células parece tener poco influencia en los patrones de colonización. Las células de Paneth encontradas en las criptas de Lieberkuhn juegan un papel significativo en la defensa antibacteriana del intestino delgado.

Flora nativa e infección intraabdominal: la peritonitis primaria sigue dos rutas: ascenso rápido desde el tracto genital inferior en mujeres y traslocación a través de una mucosa intestinal intacta en la cirrosis. En el último caso, los cambios en la composición de la flora del intestino proximal intervienen en la predisposición de dicha traslocación, como también sucede en la colonización e infección de tejido necrótico periférico en la infección pancreática. La peritonitis secundaria resulta de una alteración en la integridad de la pared intestinal, exponiendo la cavidad peritoneal al amplio espectro de organismos residentes en el tracto gastrointestinal. La peritonitis terciaria, definida como la presencia de infección recurrente después del aparente manejo adecuado de una peritonitis primaria o secundaria, está asociada con una población diferente de flora microbiana. Las especies infectantes más comunes son Sthaphylococcus coagulasa negativa, Cán- 
dida, Enteroccocus y Pseudomona, que son los frecuentes en el tracto gastrointestinal de pacientes críticamente enfermos.

\section{Peritonitis y sepsis intra-abdominal}

La peritonitis y la infección intra-abdominal no son lo mismo. La primera significa inflamación del peritoneo o parte de él por múltiples elementos como bacterias, hongos, virus, talco, fármacos, granulomas o cuerpos extraños. La segunda es la infección local del peritoneo secundaria a bacterias u hongos y se denomina sepsis intraabdominal al mismo proceso pero con una respuesta sistémica. Esta tiene dos grandes presentaciones, la primera es la peritonitis que a su vez se divide en primaria, secundaria y terciaria; la segunda es la formación de abscesos, que se caracteriza por el aislamiento del proceso infeccioso del resto de la cavidad.

\section{Clasificación de las infecciones intraabdominales}

Peritonitis primaria: es la inflamación originada en una posible fuente extraperitoneal, con frecuencia por diseminación hematógena. Se debe al deterioro de las defensas inmunitarias del huésped y por lo general es monomicrobiana. El 70\% las ocasiona E.Coli, 10 a $20 \%$ cocos gram positivos y $10 \%$ anaerobios. El manejo por lo regular incluye tratamiento médico con antibióticos y administración de líquidos. En caso de no mejorar, el paciente debe llevarse a cirugía.

Peritonitis secundaria: se clasifica en aguda por perforación, postoperatoria y postraumática. La primera es la más común y casi el $80 \%$ se debe a lesiones necróticas del tubo digestivo. Entre las causas de perforación se encuentra la úlcera péptica, la inflamación y necrosis del intestino y la apendicitis. Alrededor del 22\% son secundaria a inflamación del colon (diverticulitis y colitis) y con menor frecuencia a perforaciones por cáncer, hernia encarcelada o invaginación.

La peritonitis post-operatoria: se presenta en 10 a $20 \%$ de las intervenciones quirúrgicas del abdomen. Se debe a la filtración o dehiscencia de la anastomo- sis de la línea de sutura. Se hace evidente entre el quinto o sexto día y causa alta mortalidad. El contenido intestinal infectado y las enzimas proteolíticas pasan a la cavidad peritoneal inflamándola y produciendo la respuesta local y sistémica. Puede ocurrir que las anastomosis y las suturas estén intactas y se encuentre una peritonitis residual por diversas causas, entre estas el drenaje inadecuado del foco séptico inicial o en la incapacidad defensiva del peritoneo para controlar el problema.

Después de un trauma cerrado se puede encontrar peritonitis causada por lesiones intraabdominales no identificadas, como ruptura del mesenterio con pérdida de la irrigación del intestino delgado o grueso.

En los pacientes con trauma penetrante de abdomen en quienes se realiza cirugía y reparación en forma inmediata y se controla la herida, la contaminación secundaria no suele considerarse una infección intraabdominal a menos que el tiempo entre la herida y la cirugía sea tan largo como para desarrollar la infección. Solo la tercera parte de los pacientes con herida penetrante de colon tiene una contaminación probada de la cavidad abdominal que requiere tratamiento con antibióticos.

\section{Diagnóstico}

Se debe realizar con los datos de la historia clínica y el examen físico; el síntoma principal es el dolor abdominal que puede ser de inicio agudo o insidioso, a menudo se torna constante e intenso y se agrava con el movimiento. Aparece también anorexia, náuseas y vómito. La temperatura suele ser mayor de $38^{\circ} \mathrm{C}$, pero en pacientes con choque séptico puede haber hipotermia. Hay dolor intenso a la palpación cerca del órgano comprometido y la presencia de rebote indica con exactitud el sitio de máxima irritación peritoneal.

En el laboratorio el leucograma tiene por lo general un recuento mayor de 11.000 células por $\mathrm{mm}^{3}$ con desviación a la izquierda. En ocasiones se puede encontrar leucopenia, la cual es sugestiva de sepsis grave y mala respuesta del huésped. La química sanguínea 
suele ser normal, pero en casos graves puede haber datos indirectos de deshidratación como aumento del nitrógeno ureico en sangre. La acidosis metabólica ayuda en la confirmación del diagnóstico. Se debe realizar parcial de orina de rutina para descartar enfermedades del aparato urinario. En radiografías de abdomen se debe buscar íleo paralítico con distensión de asas intestinales, niveles hidroaéreos y líquido libre en la cavidad peritoneal. Cuando se sospecha perforación de víscera hueca el aire en la cavidad peritoneal se ve en la radiografía de tórax de pie, como es positivo en el $80 \%$ de los casos de úlcera duodenal perforada y con menos frecuencia en perforación de colon, intestino delgado o del recto intraperitoneal.

En el estudio inicial de la peritonitis aguda no se requiere realizar la tomografía axial computarizada, sin embargo puede ser útil en el diagnóstico posterior de una peritonitis postoperatoria con varios días de evolución o para identificar un absceso intra-abdominal. La ecografía puede mostrar colecciones líquidas pero es imposible diferenciar si es serosa, hemática o purulenta. Es muy importante la punción dirigida a la colección y la toma de muestras para extendidos y cultivos.

En situaciones especiales donde ni la historia clínica ni el examen físico son concluyentes, el lavado peritoneal es un método seguro y fidedigno para el diagnóstico; uno positivo con más de 500 leucocitos $/ \mathrm{mm}^{3}$, hará el diagnóstico de peritonitis. Cuando existen datos equívocos entre el clínico, paraclínico y el examen físico, queda el recurso de la laparoscopia que se puede realizar en casos seleccionados en los cuales no exista contraindicación.

\section{Tratamiento}

Los objetivos principales en la preparación preoperatoria de los pacientes con peritonitis secundaria son la restitución de líquidos y la iniciación del tratamiento con antibióticos. Todos tienen grados variables de hipovolemia para lo cual se deben administrar volúmenes de líquido adecuado, vigilando la presión arterial, la venosa y la diuresis. Es necesario medir la presión venosa central y de preferencia las dos de llenado incluyendo la de cuña pulmonar.

El tratamiento antibiótico se debe iniciar tan pronto como se confirme el diagnóstico de peritonitis, aún antes de las tomas para cultivos. La elección de los fármacos se basa en la sospecha de los microorganismos responsables y en la capacidad para alcanzar niveles adecuados en la cavidad peritoneal.

El tratamiento de una peritonitis secundaria debe incluir drogas que tengan actividad contra bacterias aeróbicas y anaeróbicas, cubriendo los siguientes gérmenes más frecuentes: bacterias aeróbicas como E.coli, Streptococcus, Enterobacter, Klebsiella, Enterococus, Proteus y las bacterias anaerobias como Bacteroides fragilis y Streptococcus. En peritonitis leve o moderada adquirida en la comunidad se puede utilizar monoterapia o combinada. Las drogas para la primera suelen ser cefoxitina o ampicilina-sulbactam, la combinada se realiza con anaerobicidas tales como el metronidazol o clindamicina con un aminoglucósido (gentamicina o amikacina). Si la infección es severa, secundaria a gérmenes resistentes e intrahospitalarios y el paciente ya ha recibido tratamiento antibiótico, utilizará el siguiente esquema: monoterapia con piperacilina tazobactam, o carbapenem como imipenem, cilastatina o meropenem. Si se emplea combinada se utilizarán antianaerobicidas (clindamicina o metronidazol) más cefalosporinas de tercera o cuarta generación, o aminoglucósidos, o la combinación de ciprofloxacina y metronidazol.

\section{Tratamiento quirúrgico}

Las metas del tratamiento quirúrgico buscan eliminar la causa de la contaminación, reducir la inoculación bacteriana y prevenir la sepsis persistente o recurrente. Se deben realizar por lo tanto lavados de la CABD con aspirado de los detritus y diferentes partículas, lavando bien los acúmulos que puedan estar en la pelvis, goteras parietocólicas y en los espacios subfrénicos, se recomienda retirar parte de la fibrina que se encuentra sobre el peritoneo, pero sin realizar 
un desbridamiento extenso que ocasione una hemorragia excesiva y daños mecánicos del intestino.

El lavado se debe realizar con solución salina, con los litros necesarios hasta que se obtenga un retorno claro del líquido peritoneal, sin usar otros materiales de lavado tales como antibióticos o soluciones yodadas que no han mostrado efectividad. Después del lavado se seca por completo para tratar de dejar la menor cantidad de líquido en el peritoneo y facilitar la acción de macrófagos y neutrófilos. Luego se procede al cierre de la cavidad usando para la fascia sutura no absorbible como prolene, aunque se pueden utilizar otros como PDS o vicryl. La piel se deja abierta y cubierta con gasas húmedas por un período de 48 a 72 horas, por el riesgo de infección de la herida quirúrgica después de una peritonitis difusa (42\%), luego de este tiempo si se encuentra limpia se afronta de nuevo realizando un cierre diferido de la herida.

Una vez suspendido el tratamiento antibiótico, el paciente debe permanecer 48 horas afebril y sin leucocitosis, considerando así que la peritonitis secundaria está resuelta. Si la evolución es insatisfactoria, y se sospecha reacumulación de material purulento en forma de absceso o peritonitis difusa, se debe decidir entre una laparotomía a demanda o seguir por etapas con abdomen abierto.

La laparotomía a demanda consiste en reoperar al paciente en forma no programada dependiendo de la evolución clínica en el postoperatorio inmediato al detectar signos y síntomas de peritonitis persistente, como dolor abdominal severo, íleo prolongado, defensa y distensión abdominal con intolerancia a la nutrición enteral, acompañados de fiebre y leucocitosis. Hay otra forma de presentación no abdominal que se manifiesta con sospecha de atelectasias, neumonía, síndrome de dificultad respiratoria del adulto (SDRA), falla renal y demanda de más ventilación mecánica, lo cual indica disfunción de órganos. La decisión de reoperar un paciente es difícil y se debe tomar en conjunto entre el cirujano, el grupo de cuidado intensivo y los radiólogos, por el dilema entre definir si las manifestaciones anteriores son un síndrome de respuesta inflamatoria sistémica (SIRS) secundario al trauma o en realidad hoy un foco intraabdominal.

Si se considera en la primera reintervención que no es posible cumplir los requisitos de prevenir la reacumulación de pus y desbridar por completo el tejido necrótico, se debe programar la laparotomía por etapas con abdomen abierto, con intervenciones cada 24 horas para revisión, lavado y drenaje de la CABD, hasta lograr controlar el foco séptico. Este procedimiento se ha denominado STAR (Staged Abdominal Repair). Se debe alcanzar el objetivo con dos a tres reintervenciones programadas cada 24 horas.

Las ventajas de la laparotomía programada con abdomen abierto son: limpiar y drenar el peritoneo como si fuera un gran absceso toda la cavidad, reducir al mínimo la relaparotomía a demanda evitando el daño de la pared abdominal, evitar la hipertensión intraabdominal y el síndrome de compartimiento abdominal, por último poder revisar y desbridar la pared abdominal si es necesario. Los inconvenientes de esta técnica son el mayor requerimiento de anestesia y la manipulación excesiva de vísceras con alta posibilidad de fístulas. El cierre definitivo del abdomen se define en el último lavado cuando se retira la malla, al observar buen tejido de granulación y estar casi o completamente bloqueada la cavidad abdominal.

Peritonitis terciaria: se define como la persistencia o recurrencia de la infección intraabdominal luego del tratamiento, en apariencia adecuado, de una peritonitis primaria o secundaria. La infección persiste o recurre después de 48 horas del tratamiento quirúrgico y uso antibiótico adecuado. También se considera aquella que continúa después de la tercera reintervención por peritonitis secundaria mediante laparotomía por etapas. En el lavado peritoneal se encuentran gérmenes y cuando los hay son de baja virulencia y cambiantes con el tiempo pues la CABD no se defiende. El cuadro clínico corresponde a una sepsis oculta manifestada por un estado cardiovascular hiperdinámico, fiebre baja e hipermetabolismo. 
Al cultivar el líquido peritoneal se encuentran gérmenes como el Stafilococcus coagulasa negativo, Enterococcus, Pseudomona, hongos y Enterobacter entre otros.

El manejo de la peritonitis terciaria se debe realizar en UCI con adecuado soporte metabólico, nutricional, ventilatorio, hemodinámico y respiratorio, además de cambiar los antibióticos según el reporte de hemocultivos y cultivos de la CABD. Es vital decidir cuando reintervenir y cuántas veces se justifica reoperar, pues los lavados pueden hacer más daño que beneficio después del quinto procedimiento. Es importante programar el uso de antimicrobianos por un tiempo prudencial, pues es muy posible que sean inútiles luego de dos o tres semanas, excepto para el manejo de los hongos.

\section{Abscesos intra-abdominales}

Representan una defensa efectiva de la CABD cuando la lesión tisular y el número de bacterias sobrepasan la capacidad del huésped para suprimir una infección peritoneal. Durante la fase inflamatoria inicial hay exudación de plasma y fibrina, los macrófagos aumentan el depósito de esta última, originando agregación celular y adherencia al peritoneo. Al progresar la infección, la fibrina se deposita con mayor rapidez de lo que se destruyen las toxinas bacterianas y origina la creación de una membrana biológica. Los leucocitos pueden obstruir las válvulas linfáticas y evitar la eliminación de pus a través de canales linfáticos diafragmáticos y se forman abscesos subfrénicos.

El contenido del absceso se licúa por las enzimas proteolíticas de los fagocitos muertos y las toxinas y enzimas de las bacterias, aumentando la presión osmótica que atrae agua y aumenta la presión dentro de la cápsula. Se promueve entonces la glucólisis anaerobia originando un ambiente anerobio con presión, $\mathrm{pH}$, oxígeno y $\mathrm{CO}^{2}$ altos.

Clínica y diagnóstico: se caracteriza por fiebre persistente, sobre todo en picos, dolor sordo, anorexia y pérdida de peso. Hay leucocitosis y en ocasiones deterioro de la función de los órganos vecinos, con edema y derrame pleural. La TAC y la ecografía son los métodos diagnósticos de los abscesos intraabdominales, cada uno con ventajas y desventajas. La segunda es un medio rápido y económico, con localización exacta del líquido extraintestinal. La desventaja es que es operador dependiente, con imágenes poco definidas por el gas intestinal y resulta difícil de interpretar con heridas abiertas o drenaje. La principal ventaja es mostrar las estructuras intraperitoneales y retroperitoneales con un alto grado de resolución y exactitud. La mayor desventaja es que no es portátil y exige cooperación del paciente. La exactitud de la tomografía es menor en quienes no reciben medios de contraste.

Tratamiento: el drenaje percutáneo es una alternativa terapéutica con una tasa de éxito entre 80 y $90 \%$. El uso exclusivo de antibióticos suele fracasar y solo es útil cuando se realiza temprano y existe una inflamación flegmonosa localizada sin pus. Una vez que esta se produce y se localiza, debe drenarse para evitar el riesgo de ruptura. Se considera que los drenajes percutáneo y quirúrgico son técnicas complementarias. Las fallas del drenaje percutáneo son la obstrucción del catéter, la punta desubicada, presencia de abscesos múltiples, remoción prematura del catéter y la inexperiencia del operador.

El desbridamiento y limpieza peritoneal se refiere al mecanismo de remover material desvitalizado y extraño de la CABD. Existen grados diferentes de agresividad en su realización. Las operaciones convencionales consisten en el retiro del tejido infectado y del material no viable de la CABD con mecanismos simples tales como succión y lavado, con o sin agentes antimicrobianos en el líquido empleado. El lavado continuo peritoneal se refiere a la instilación de fluido (y drenaje) a través de catéteres dentro de la CABD con el propósito de introducir y remover en forma simultánea largos volúmenes de cristaloides. El desbridamiento peritoneal radical comprende la succión e irrigación más la meticulosa remoción de todo material sólido como fibrina y 
contaminantes que estén adheridos a la superficie. El drenaje peritoneal abierto, también conocido como laparostomía, es cuando el cirujano no cierra la fascia abdominal dejando las vísceras cubiertas con bolsa pero relativamente expuestos al medio ambiente. Las reoperaciones programadas se refieren a una serie de exploraciones seriadas de la CABD.

\section{Desafío de infecciones en el huésped}

El grado de contaminación peritoneal se correlaciona con la severidad de la infección y el resultado. Estudios clínicos y experimentales en animales en una variedad de condiciones infecciosas han demostrado que las altas concentraciones de patógenos microbianos contaminantes llevan a una infección más severa. Así, la densidad de un inóculo bacteriano se correlaciona con la severidad de la infección y determina el resultado final junto con la comorbilidad del paciente, los mecanismos de defensa del huésped y el tratamiento. Como se mencionó antes, en peritonitis secundaria los contaminantes no sólo incluyen los patógenos microbianos, sino también sustancias no viables que incrementan la severidad de la infección, como los fluidos contaminantes (sangre, bilis, comida, heces), los productos del huésped (tejido necrótico, sangre, fibrina) o bien la presencia de material radiológico (bario).

\section{Respuesta del huésped a la infección}

El huésped responde de dos maneras: absorción de bacterias a la sangre vía linfática y la inflamación local aguda peritoneal. La absorción sistémica de microorganismos de la CABD ayuda a la eliminación de patógenos a través de la acción de células fagocíticas, en especial macrófagos hepáticos (células de Kupffer), mientras recupera la anatomía y fisiología peritoneales. Como se explicó, la absorción del peritoneo es mediada por linfáticos y ocurre a los pocos minutos de una contaminación. Este mecanismo puede neutralizar pequeños inóculos bacterianos sin llevar a una exagerada respuesta inflamatoria.

Una gran cantidad de inóculos puede generar una respuesta sistémica. Cuando se absorbe por completo se produce una respuesta secundaria con inflamación de la serosa, muerte local bacteriana intraperitoneal y atrapamiento de las bacterias en la fibrina, que significa exteriorizar la bacteria del cuerpo y limitar su crecimiento.

\section{Desbridamiento racional del peritoneo}

La función de la limpieza peritoneal es controlar la infección inicial removiendo los microbios y las sustancias que puedan causar daño a los tejidos. El método más común de desbridamiento agresivo ha sido el lavado continuo postoperatorio de la cavidad abdominal abierta (laparostomía) y la reoperación programada. Es infortunado que los estudios clínicos no han logrado estratificar los pacientes por la severidad de su enfermedad y ha sido imposible ajustar el resultado de acuerdo con el tiempo adecuado para los siguientes controles. Algunos estudios, pero no todos, han reportado resultados favorables. El desbridamiento de todos los contaminantes y depósitos de fibrina de la superficie peritoneal podría reducir el número de bacterias patógenas. Sin embargo, análisis comparativos con la terapia estándar no han mostrado beneficio.

La laparostomía también tiene datos a favor y en contra, con resultados exitosos y otros discutibles. Lo racional del procedimiento es tratar la cavidad como un "absceso" para ser drenado como una entidad simple. La reoperación programada ha sido descrita en dos circunstancias distintas. Cuando no se puede realizar cierre primario por inadecuada tensión de las estructuras intraabdominales debido a la severa infección, o bien por la pérdida de la fascia debido a hernia ventral previa o infección de ella. En tal caso el cierre de la pared abdominal se realizará una vez la infección se haya controlado.

La otra indicación para la reoperación programada es el tratamiento de la infección severa. Con este fin la pared se cierra con un dispositivo que permita múltiples reentradas al abdomen. Los potenciales resultados adversos son la fístula y la hernia incisional. 


\section{Consecuencias de la falla en el control de la fuente de infección}

Algunos casos de infección incontrolable se atribuyen a sepsis y falla de la respuesta del huésped, mientras otros son complicaciones específicas de la infección. La hipovolemia, intolerancia a los carbohidratos y la disfunción orgánica son ejemplos de consecuencias adversas genéricas, mientras el síndrome compartimental, fístula enterocutánea y amputación son ejemplos de consecuencias específicas. Algunas pueden estar interrelacionadas, tales como disfunción orgánica con síndrome abdominal.

Las consecuencias de la falla en el control de una infección intraabdominal son graves e incluyen la posibilidad de muerte. Algunas complicaciones son secundarias a la infección, mientras otras son iatrogénicas. La magnitud de la falla también puede estar relacionada con el tiempo de reintervención, el cual depende del índice de sospecha y el diagnóstico rápido.

La infección incontrolada puede progresar muy rápido a causa de falla en las defensas del huésped y la elaboración de proteasas por patógenos. Puede invadir los planos de los tejidos naturales y también los quirúrgicos. La infección de la herida quirúrgica no siempre indica una falla en el control, pero si existe es un riesgo para desarrollar infección necrotizante de la herida quirúrgica.

Rara vez una infección incontrolada puede penetrar dentro de otra estructura intra-abdominal. Por ejemplo, abscesos de colecistitis que infiltran el hígado. Los procedimientos quirúrgicos necesarios para lograr el control de la infección tienen numerosas complicaciones inherentes. El drenaje percutáneo puede producir ruptura de un absceso llevando a una bacteriemia o a una peritonitis generalizada. Si la perforación se comunica libremente con el absceso, puede resultar una fístula a lo largo del trayecto del catéter. La infección necrotizante de los tejidos blandos se presenta en forma insidiosa pero progresa con rapidez. El desbridamiento inicial debe extenderse hasta los tejidos normales y se debe estar atento, aunque la progresión se haya detenido, a la posibilidad de una fuente intraabdominal.

Síndrome de respuesta inflamatoria sistémica: la manifestación más común de un control inadecuado es la persistencia y recurrencia de signos o síntomas de infección. El SIRS puede persistir pocos días después de una intervención exitosa en la infección intraabdominal. La persistencia de SIRS se asocia con la alta morbilidad y mortalidad del síndrome de disfunción orgánica múltiple (MODS).

Hipovolemia, isquemia y reperfusión: la interacción mediada por citoquinas entre neutrófilos y células endoteliales lleva a un incremento de la permeabilidad microvascular con exudación y acumulación de fluidos sistémicos en la CABD, que conllevan a la vasodilatación sistémica y disfunción ventricular izquierda. Los órganos susceptibles de isquemia son los riñones y las vísceras gastrointestinales incluyendo hígado, vejiga, páncreas y colon, aunque el corazón y el músculo esquelético también lo son. Las consecuencias de una reanimación con alta carga de volumen incluyen hipoalbuminemia, anemia, edema de tejidos, síndrome compartimental y disfunción cardiovascular.

La hipoalbuminemia se produce por causa dilucional y en parte por una disminución en la síntesis en la fase de respuesta aguda. La sepsis y las intervenciones quirúrgicas electivas están relacionadas con el síndrome de resistencia a la insulina y la hiperglicemia resultante puede causar hipovolemia por diuresis osmótica, y en casos severos cetoacidosis y alteración del estado mental; también se asocia con un incremento en la incidencia de infección nosocomial.

La infección nosocomial puede desarrollarse en el sitio de la cirugía o en uno remoto. En el primer evento puede estar causado por el patógeno original, por la flora nosocomial, como $S$. aureus meticilino resistente, bacilos gram negativos entéricos resistentes a múltiples drogas (Enterobacteriaceas, Pseudomona aeruginosa), enterococcos y yersinia, así como por organismos oportunistas y superinfección de tejidos blandos necrosados. Existe alto riesgo de infección 
nosocomial remota del sitio quirúrgico. La neumonía es común y está relacionada a la duración de la ventilación mecánica y al uso previo de antibióticos.

La peritonitis terciaria (nosocomial) es otra manifestación de incompetencia de los mecanismos de control. Algunos autores la consideran como una falla en los mecanismos de defensa con la colonización de la CABD. Un factor de riesgo común para todas las infecciones nosocomiales es el uso de antibióticos y cada curso terapéutico incrementa el riesgo de superinfección resistente a drogas.

Disfunción orgánica múltiple: muchos pacientes con falla en el control pueden tener algún grado de síndrome de disfunción orgánica múltiple (MODS), que está asociado con muerte por infección incontrolada. La activación de mediadores de respuesta inflamatoria por citoquinas, quimiocinas, eicosanoides, moléculas de adhesión, factores de coagulación e intermediarios de oxígeno y nitrógeno, pueden ocluir la circulación. Las manifestaciones del MODS son variables y consisten en inestabilidad hemodinámica (cardiovascular), estupor o coma (sistema nervioso central), trombocitopenia (coagulación), colestasis (hepático), hipoxemia (pulmonar) y azoemia (renal). El riesgo de hospitalización prolongada, infección nosocomial recurrente y muerte, esta directamente relacionada con el número de órganos afectados y en especial el alto grado de disfunción de órganos. El mejor tratamiento es la prevención, el tiempo y la efectividad de reanimación y la rápida resolución del SIRS.

\section{Lecturas recomendadas}

* Christou NV, Barie PS, Dellinger EP, Waymack JP, Stone HH. Surgical Infection Society intra-abdominal infection study. Prospective evaluation of management techniques and outcome. Arch Surg. 1993 Feb;128(2):193-8.

* Malangoni MA. Evaluation and management of tertiary peritonitis. Am Surg. 2000 Feb;66(2):157-61.

* Moore EE, Burch JM, Franciose RJ, Offner PJ, Biffl WL. Staged physiologic restoration and damage control surgery. World J Surg. 1998 Dec;22(12):1184-90.

* Solomkin JS, Mazuski JE, Baron EJ, Sawyer RG, Nathens AB, DiPiro JT, Buchman T, Dellinger EP, Jernigan J, Gorbach S, Chow AW, Bartlett J; Infectious Diseases Society of America. Guidelines for the selection of anti-infective agents for complicated intra-abdominal infections. Clin Infect Dis. 2003 Oct 15;37(8):997-1005.

* Walker RI, Owen RL. Intestinal barriers to bacteria and their toxins. Annu Rev Med. 1990;41:393-400.

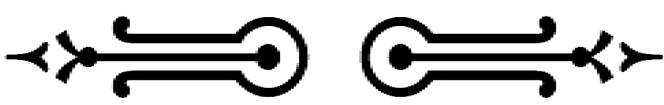

